\title{
Posttraumatic Stress Disorder, Depression, and HIV Risk Behavior Among Ohio Army National Guard Soldiers
}

\author{
Brandon D. L. Marshall, ${ }^{1,2}$ Marta R. Prescott, ${ }^{1}$ Israel Liberzon, ${ }^{3,4}$ Marijo B. Tamburrino, ${ }^{5}$ \\ Joseph R. Calabrese, ${ }^{6}$ and Sandro Galea ${ }^{1}$ \\ ${ }^{1}$ Department of Epidemiology, Columbia University Mailman School of Public Health, New York, New York, USA \\ ${ }^{2}$ Department of Epidemiology, Brown University, Providence, Rhode Island, USA \\ ${ }^{3}$ Department of Psychiatry, University of Michigan, Ann Arbor, Michigan, USA \\ ${ }^{4}$ Veterans Affairs Medical Center, Ann Arbor, Michigan, USA \\ ${ }^{5}$ Department of Psychiatry, University of Toledo College of Medicine, Toledo, Ohio, USA \\ ${ }^{6}$ Case Western Reserve University, University Hospitals Case Medical Center, Cleveland, Ohio, USA
}

\begin{abstract}
We examined the relationship between posttraumatic stress disorder (PTSD), major depressive disorder (MDD), and human immunodeficiency virus (HIV) risk behavior among the Ohio Army National Guard (OHARNG). We analyzed data collected from a sample of OHARNG enlisted between June 2008 and February 2009. Participants completed interviews assessing HIV risk activities defined by the Behavioral Risk Factor Surveillance System, and were screened for PTSD and MDD based on DSM-IV criteria according to the Diagnostic and Statistical Manual of Mental Disorders (4th ed., DSM-IV; American Psychiatric Association, 1994). Logistic regression was used to examine the independent and combined effects of PTSD and MDD on past-year HIV risk behavior. Of 2,259 participants, 142 (6.3\%) reported at least 1 past-year HIV risk behavior. In adjusted models, relative to soldiers with neither disorder, screening positive for MDD only was associated with HIV risk behavior (adjusted odds ratio $[A O R]=2.33,95 \% \mathrm{CI}=[1.15,4.71]$ ), whereas PTSD was not significant $(A O R=1.60,95 \% \mathrm{CI}=[0.80,3.20])$. Participants with both PTSD and depression were most likely to report HIV risk behavior (AOR $=2.75,95 \% \mathrm{CI}=[1.06,7.11])$. Soldiers with PTSD and MDD may be at greater risk for HIV infection due to increased engagement in HIV risk behavior. Integrated interventions to address mental health problems and reduce HIV risk behavior are in need of development and evaluation.
\end{abstract}

Posttraumatic stress disorder (PTSD) has long been recognized as a debilitating condition that adversely affects physical and psychological health (Breslau, Davis, Peterson, \& Schultz, 1997; Davidson, Hughes, Blazer, \& George, 1991; Zatzick et al., 1997). The development of PTSD is associated with a variety of health behaviors (e.g., smoking, alcohol and substance use, physical inactivity) that increase the risk of morbidity and mortality (Breslau, Davis, \& Schultz, 2003; Buckley, Mozley, Bedard, Dewulf, \& Greif, 2004;

\footnotetext{
The research was supported by the U.S. Department of Defense congressionally directed medical research program (W81XWH-O7-1-0409, the "Combat Mental Health Initiative") and a fellowship award from the Canadian Institutes of Health Research. We wish to thank soldiers of the Ohio Army National Guard who participated in this study for contributing to the research.
}

Correspondence concerning this article should be addressed to Brandon D. L. Marshall, Department of Epidemiology, Brown University, 121 South Main Street, Box G-S-121-2, Providence, RI, 02912. E-mail: brandon_marshall@brown.edu

Copyright (c) 2013 International Society for Traumatic Stress Studies. View this article online at wileyonlinelibrary.com

DOI: $10.1002 /$ jts. 21777
Schnurr \& Spiro, 1999). A growing body of literature has also shown that persons who develop PTSD following exposure to trauma are more likely to participate in HIV risk behaviors (Brief et al., 2004). For example, a lifetime occurrence of PTSD has been associated with recent engagement in receptive anal intercourse and sex work among women prisoners (Hutton et al., 2001). A study of women who had experienced intimate partner violence (IPV) demonstrated that IPV-related PTSD was significantly associated with a composite measure of sexual risk behavior, and was particularly elevated among women with avoidance and numbing symptoms (Cavanaugh, Hansen, \& Sullivan, 2010). Similar results have been reported among women seeking emergency care in New York City (El-Bassel, Gilbert, Vinocur, Chang, \& Wu, 2011). Although fewer studies have examined the relationship between PTSD and HIV risk among men, some evidence indicates that PTSD increases the risk of unprotected anal intercourse in men who have sex with men (Reisner, Mimiaga, Safren, \& Mayer, 2009).

Depression is also widely reported as a risk factor for engagement in HIV risk behavior in the general and at-risk populations (Alegría et al., 1994; Lehrer, Shrier, Gortmaker, \& Buka, 
2006; Perdue, Hagan, Thiede, \& Valleroy, 2003; Williams \& Latkin, 2005). Despite the high prevalence of mental health comorbidities in many populations affected by HIV, research has typically focused on the independent effects of PTSD and depression in people living with or at risk for the disease (Boarts, Sledjeski, Bogart, \& Delahanty, 2006). Several authors have examined the influence of comorbid conditions on adherence to HIV therapy, with two studies suggesting that depression plays a more important role in poor adherence than PTSD (Sledjeski, Delahanty, \& Bogart, 2005; Vranceanu et al., 2008). Although some evidence suggests that HIV risk behaviors are particularly common among persons experiencing co-occurring depression and PTSD (Holmes, Foa, \& Sammel, 2005; Plotzker, Metzger, $\&$ Holmes, 2007), these studies have focused on persons with childhood abuse histories. Therefore, more research is required to determine the unique and combined contributions of PTSD and depression on risk behavior in other populations at risk for HIV.

The objective of this study was to examine whether depression and PTSD were associated with increased engagement in HIV risk behavior among a sample of Ohio Army National Guard (OHARNG) soldiers. We also sought to determine whether soldiers with both disorders were more likely to report HIV risk behavior compared to participants reporting one or neither conditions. Although studies of active U.S. army personnel and armed forces in other countries have investigated HIV prevalence and risk factors for HIV infection including PTSD (Anastario et al., 2011; Levin et al., 1995; Tavarez, Chun, \& Anastario, 2011), to our knowledge no studies have examined the relationships between depression, PTSD, and HIV risk behavior in soldiers of the U.S. National Guard. Given the high prevalence of trauma exposure and subsequent PTSD among National Guard soldiers (Calabrese et al., 2011; Kehle et al., 2011), elucidating the relationships between mental health problems and HIV risk behavior has important implications for the development of effective HIV prevention services for military personnel.

\section{Method}

\section{Participants and Procedure}

Between November 2008 and November 2009, OHARNG soldiers were recruited to participate in the OHARNG Mental Health Initiative. For the present study, all enlisted soldiers between June 2008 and February 2009 with a current address $(12,225)$ were mailed a letter explaining the study's objectives and consenting procedures along with a prepaid opt-out card. We excluded 1,013 (8.3\%) who returned an opt-out card, 1,130 $(9.2 \%)$ who did not have a telephone number listed with the Guard, and 3,568 (29.2\%) who had an incorrect telephone number. Of the 6,514 participants remaining, 1,364 (20.9\%) refused to participate, 218 (3.3\%) were excluded for other reasons (i.e., were deceased, did not speak English, had hearing problems, or were retired), and 2,316 (35.6\%) were not contacted before the cohort closed. Thus, the eligible sample was 2,616.

To examine the effect of PTSD and new onset MDD after experiencing a qualifying trauma, we used timing of symptom onset data to exclude participants who reported having depressive symptoms prior to the date of experiencing a Criterion A stressor $(n=39)$. We also excluded participants for whom the timing of onset of the trauma and depression could not be differentiated $(n=44)$, or who were missing the timing of the trauma or onset of PTSD and MDD symptoms $(n=22)$. We further excluded 141 participants who had never experienced a qualifying traumatic event, and 111 participants who had nonresponses to any of the model confounding variables of interest (see below). Therefore, the final sample was $N=2,259$, of whom, the majority were male $(86.0 \%)$, White $(88.1 \%)$, and less than 35 years of age $(64.7 \%)$.

Computer-assisted telephone interviewing (CATI) was used to collect a wide array of information regarding sociodemographic characteristics, risk behaviors, military history, deployment and combat experiences, and past and present psychopathological symptoms. Interviews took approximately 60 minutes to complete and all participants were compensated for their time.

The study received a certificate of confidentiality from the National Institutes of Health, and the study protocol was approved by the Institutional Review Boards of University Hospitals Case Medical Center, University of Toledo, and Columbia University. The study was also approved by the Human Research Protection Office (HRPO), Office of Research Protections (ORP), and the U.S. Army Medical Research \& Materiel Command (USAMRMC) of the U.S. Department of Defense. Verbal informed consent was obtained from all participants.

\section{Measures}

HIV risk. The dependent variable for this analysis was self-reported participation in HIV risk behavior(s) in the past year (yes vs. no). To define this variable, we used a standardized set of core questions from the Behavioral Risk Factor Surveillance System (BRFSS), a U.S. Centers for Disease Control and Prevention (CDC)-supported general population survey that includes measures of HIV/STD risk behaviors (Centers for Disease Control and Prevention, 2011). Core items included in the HIV/acquired immunodeficiency syndrome (AIDS) section of the BRFSS were developed by a 1997 CDC working group and were chosen after extensive cognitive laboratory testing and field piloting (Rietmeijer, Lansky, Anderson, \& Fichtner, 2001). To assess HIV risk behaviors, participants were asked whether they had engaged in any of the following in the past year: (a) used intravenous drugs, (b) been treated for a sexually transmitted or venereal disease, (c) given or received money or drugs in exchange for sex, and (d) had anal sex without a condom. To be consistent with BRFSS methodology and with previously published studies using this measure (Bensley, Van Eenwyk, \& Simmons, 2000; Link, Battaglia, Frankel, Osborn, 
\& Mokdad, 2006; Wen, Balluz, \& Town, 2012), participants were informed that they did not have to identify which risk(s) they had practiced in the past year. All participants provided a yes or no answer to the question (no nonresponses or refusals were recorded).

Psychiatric symptoms. The primary independent variables of interest were screening positive for PTSD and major depressive disorder (MDD), each based on DSM-IV criteria. Specifically, a positive screen for PTSD was assessed using the PTSD Checklist-Civilian Version (PCL-C), modified to include questions that assessed DSM-IV diagnostic Criteria A2, E, and F (Blake et al., 1995). Thus, participants screening positive for PTSD must have met all DSM-IV criteria related to a specific traumatic event: been exposed to a Criterion A stressor (e.g., a traumatic event involving actual or threatened death or serious injury), had at least one intrusion symptom (e.g., recurrent distressing recollections or dreams of the event), had at least three symptoms of avoidance (e.g., avoiding activities, places, or people associated with the trauma), and had at least two hyperarousal symptoms (e.g., difficulty falling asleep, hypervigilance). Based on questions that assessed duration, symptoms must also have lasted for at least a month. Participants must also have reported that symptoms caused significant social or functional impairment (e.g., very difficult to perform tasks at work, at home, or get along with others). The PCL-C has been found to be a reliable and valid instrument in both general and military personnel populations (Blanchard, Jones-Alexander, Buckley, \& Forneris, 1996; Maguen et al., 2010). We assessed MDD using the Primary Care Evaluation of Mental Health Disorders Patient Health Questionnaire-9 (PHQ-9; Kroenke \& Spitzer, 2002; Kroenke, Spitzer, \& Williams, 2001). To screen positive for MDD, a participant had to score $\geq 5$ of nine symptoms on the PHQ-9, and these symptoms had to occur together within a 2-week period along with either depressed mood or anhedonia. In addition to the PCL-C and PHQ-9, we also asked participants to report the year during which the Criterion A traumatic event was experienced and the age of onset of PTSD and depressive symptoms. These timing data were used to identify a study sample consisting only of participants who experienced their first major depressive disorder following a qualifying traumatic event.

The following variables were also included as possible confounds: gender (female vs. male), age, marital status (never married, divorced/separated/widowed, married), race (White, Black, other), annual income ( $\leq \$ 60,000$ vs. $>\$ 60,000$ ), education (high school graduate, some college, college/graduate degree), insurance status (noninsured vs. insured), history of alcohol abuse based on DSM-IV criteria with onset prior to the PTSD-related traumatic event (yes vs. no), and deployment history (deployed vs. never deployed). Although men who have sex with men including those in the active and reserve forces are disproportionately affected by HIV (Levin et al., 1995), the survey did not assess same sex behavior and therefore we were unable to include this variable as a possible confounder.
Clinical interview. In addition to the CATI interviews and as part of the larger study, in-person clinical assessments were conducted on a random subsample of 500 participants. Master's- or doctoral-level clinicians fully consented the participants and conducted the clinical interviews. After consent was obtained, clinicians conducted the interviews in a location chosen by the participant. HIV risk behaviors were assessed using the same set of BRFSS questions listed in the telephone survey; however, in addition to the global measure of HIV risk (i.e., reporting one or more risk activities), participants completing the clinical interview were also asked to identify the specific set of behavior(s) in which they had engaged.

The Structured Clinical Interview for DSM-IV Disorders (SCID) was used to conduct detailed psychopathology assessments in the clinical subsample (First, Spitzer, Gibbon, \& Williams, 2002). In the clinical reappraisal of the CATI assessments, we observed high specificity for PTSD (92\%) and MDD (97\%), and also found high internal consistency for PTSD ( $\alpha$ $=.93)$ and good internal consistency for MDD $(\alpha=.66$; Calabrese et al., 2011). Clinical interviews typically lasted 2 hours and participants were compensated per hour for their time.

\section{Data Analysis}

As a first step, we compared the characteristics of persons reporting past-year HIV risk behavior with those reporting no risk behavior using chi-square tests or Fisher's exact test in the case of expected cell counts $\leq 5$ in more than $20 \%$ of the cells. To examine the level of agreement between HIV risk behaviors reported during the CATI and those during the in-person interviews, we computed the kappa coefficient for responses from all participants who completed both types of assessments. To determine the independent and combined effects of PTSD and MDD, we then constructed an indicator variable consisting of four mutually exclusive categories: neither PTSD nor MDD, MDD only, PTSD only, and both PTSD and MDD. This variable was then included in a multivariable logistic regression model, adjusting for all other variables hypothesized a priori as possible confounders. All statistical analyses were conducted in SAS 9.2; all $p$ values are two-sided.

\section{Results}

\section{Sample Characteristics}

The lifetime prevalence of PTSD in the sample was $7.9 \%$ $(n=178)$, and 145 persons $(6.4 \%)$ screened positive for MDD. Past-year HIV risk behavior was reported by 142 participants $(6.3 \%, 95 \%$; $\mathrm{CI}=[5.3,7.3])$. As shown in Table 1, the subsample of participants with PTSD was more likely to report past-year HIV risk behavior, $\chi^{2}(1, N=2,259)=9.97, p=$ .002 , as were those with posttraumatic event MDD, $\chi^{2}(1, N=$ $2,259)=7.78, p=.005$. Participants reporting HIV risk behavior were also more likely to be female, younger, single or of divorced/separated/widowed marital status, non-White, have 
Table 1

Factors Associated With Reporting Past Year HIV Risk Behavior in Ohio Army National Guard Soldiers

\begin{tabular}{|c|c|c|c|c|c|}
\hline \multirow[b]{2}{*}{ Variable } & \multicolumn{2}{|c|}{$\begin{array}{l}\text { HIV risk } \\
\text { behavior } \\
(n=142)\end{array}$} & \multicolumn{2}{|c|}{$\begin{array}{c}\text { No HIV risk } \\
\text { behavior } \\
(n=2,117)\end{array}$} & \multirow[b]{2}{*}{$x^{2}$} \\
\hline & $n$ & $\%$ & $n$ & $\%$ & \\
\hline PTSD & & & & & $9.97 * *$ \\
\hline No & 121 & 85.2 & 1960 & 92.6 & \\
\hline Yes & 21 & 14.8 & 157 & 7.4 & \\
\hline MDD & & & & & $7.78 * *$ \\
\hline No & 125 & 88.0 & 1989 & 94.0 & \\
\hline Yes & 17 & 12.0 & 128 & 6.0 & \\
\hline Sex & & & & & $4.06^{*}$ \\
\hline Men & 114 & 80.3 & 1828 & 86.3 & \\
\hline Women & 28 & 19.7 & 289 & 13.7 & \\
\hline Age (years) & & & & & $28.13 * *$ \\
\hline $17-24$ & 69 & 48.6 & 638 & 30.1 & \\
\hline $25-34$ & 47 & 33.1 & 707 & 33.4 & \\
\hline $35-44$ & 22 & 15.5 & 548 & 25.9 & \\
\hline$\geq 45$ & 4 & 2.8 & 224 & 10.6 & \\
\hline Marital status & & & & & $33.98 * *$ \\
\hline Married & 38 & 26.8 & 1086 & 51.3 & \\
\hline $\begin{array}{l}\text { Divorced/separated/ } \\
\text { widowed }\end{array}$ & 15 & 10.5 & 197 & 9.3 & \\
\hline Never married & 89 & 62.7 & 834 & 39.4 & \\
\hline Race & & & & & 5.72 \\
\hline White & 117 & 82.4 & 1874 & 88.5 & \\
\hline Black & 17 & 12.0 & 145 & 6.9 & \\
\hline Other & 8 & 5.6 & 98 & 4.6 & \\
\hline Income & & & & & $9.61 * *$ \\
\hline$\leq \$ 60,000$ & 100 & 70.4 & 1210 & 57.2 & \\
\hline$>\$ 60,000$ & 42 & 29.6 & 907 & 42.8 & \\
\hline Education & & & & & 2.24 \\
\hline High school graduate & 41 & 28.9 & 561 & 26.5 & \\
\hline Some college & 72 & 50.7 & 1001 & 47.3 & \\
\hline $\begin{array}{l}\text { College/graduate } \\
\text { degree }\end{array}$ & 29 & 20.4 & 555 & 26.2 & \\
\hline History of alcohol abuse $\mathrm{a}^{\mathrm{a}}$ & & & & & $7.83 * *$ \\
\hline No & 134 & 94.4 & 2074 & 98.0 & \\
\hline Yes & 8 & 5.6 & 43 & 2.0 & \\
\hline Insurance status & & & & & 1.17 \\
\hline Insured & 123 & 86.6 & 1895 & 89.5 & \\
\hline Noninsured & 19 & 13.4 & 222 & 10.5 & \\
\hline Deployment history & & & & & 2.23 \\
\hline Never deployed & 54 & 38.0 & 677 & 32.0 & \\
\hline Deployed & 88 & 62.0 & 1440 & 68.0 & \\
\hline
\end{tabular}

Note. $\mathrm{HIV}=$ human immunodeficiency virus; $\mathrm{PTSD}=$ posttraumatic stress disorder; $\mathrm{MDD}=$ major depressive disorder.

${ }^{a}$ Only consider as yes those with onset prior to PTSD-related traumatic event. $* p<.05 . * * p<.01 . * * * p<.001$. lower annual income, and report a history of alcohol abuse (see Table 1).

\section{Multivariate Analysis}

The results of the multivariate logistic regression analysis are shown in Table 2. After adjustment for selected characteristics, screening positive for MDD (in the absence of PTSD) was found to be positively and independently associated with HIV risk behavior, adjusted odds ratio $[A O R]=2.3,95 \%$ $\mathrm{CI}=[1.2,4.7]$, compared to participants with neither condition. Posttraumatic stress disorder (in the absence of MDD) was not statistically significant, $A O R=1.6,95 \% \mathrm{CI}=[0.8$, 3.2]. Finally, participants screening positive for both PTSD and MDD were most likely to report HIV risk behavior, $A O R=2.7$, $95 \% \mathrm{CI}=[1.1,7.1]$.

Clinical sample characteristics. Among the subsample of 500 participants who completed the in-person clinical assessment, HIV risk behavior data was assessed and collected from 310 . Of these participants, $24(8.1 \%)$ reported engaging in at least one HIV risk behavior $(95 \% \mathrm{CI}=[5.1 \%, 11.1 \%])$. In total, $16(5.2 \%)$ reported unprotected anal intercourse, $9(2.9 \%)$ reported being treated for a sexually transmitted disease, $4(1.3 \%)$ had used intravenous drugs, and none reported exchanging sex for money or drugs in the past year. Of participants who completed both the CATI and in-person interviews, the level of agreement for reported HIV risk behavior was fair, $\kappa=.58$, $95 \% \mathrm{CI}=[.41, .75]$.

\section{Discussion}

In this study of the Ohio Army National Guard, we observed a high prevalence of self-reported participation in HIV risk behavior. Screening positive for either PTSD or depression was found to be correlated with this outcome. Finally, soldiers reporting both PTSD and MDD after experiencing a traumatic event were most likely to report past-year HIV risk behavior.

The prevalence of HIV risk behavior observed in this study $(6.4 \%)$ is higher than that found in a nationally representative sample of U.S. adults conducted in 2005, in which $4.0 \%$ reported past-year engagement in at least one of the HIV risk behaviors included in the BRFSS (Ohl \& Perencevich, 2011). Interestingly, our results are comparable to the prevalence of BRFSS HIV risk behaviors found in other populations with adverse life experiences and exposure to trauma, including survivors of childhood abuse (7.6\%), IPV (7.4\%), and childhood cancer (8.3\%; Bensley et al., 2000; Breiding, Black, \& Ryan, 2008; Phillips-Salimi, Lommel, \& Andrykowski, 2012). Given that over $90 \%$ of the OHARNG cohort has experienced at least one traumatic event (Calabrese et al., 2011), the comparable prevalence reported here to those observed in these studies is not entirely unexpected. It is also likely that the young and predominantly unmarried sociodemographic profile of the cohort, 
Table 2

Multivariate Logistic Regression of Factors Associated With Reporting Past-Year HIV Risk Behavior

\begin{tabular}{|c|c|c|c|c|c|}
\hline Variable & $B$ & $S E$ & $A O R$ & $95 \% \mathrm{CI}$ & Wald $\chi^{2}$ \\
\hline \multicolumn{6}{|l|}{ PTSD and MDD ${ }^{\mathrm{a}}$} \\
\hline PTSD only & 0.47 & 0.35 & 1.60 & {$[0.80,3.20]$} & 1.75 \\
\hline MDD only & 0.85 & 0.36 & 2.33 & {$[1.15,4.71]$} & $5.54 *$ \\
\hline PTSD and MDD & 1.01 & 0.49 & 2.75 & {$[1.06,7.11]$} & $4.32 *$ \\
\hline \multicolumn{6}{|l|}{$\operatorname{Sex}^{\mathrm{b}}$} \\
\hline Women & 0.09 & 0.24 & 1.10 & {$[0.69,1.74]$} & 0.69 \\
\hline \multicolumn{6}{|l|}{$\operatorname{Age}^{\mathrm{c}}$} \\
\hline $25-34$ & -0.38 & 0.24 & 0.69 & {$[0.43,1.11]$} & 2.40 \\
\hline $35-44$ & -0.72 & 0.36 & 0.48 & {$[0.25,0.93]$} & $4.68 *$ \\
\hline$\geq 45$ & -1.52 & 0.57 & 0.22 & {$[0.07,0.67]$} & $7.04 * * *$ \\
\hline \multicolumn{6}{|l|}{ Marital status ${ }^{\mathrm{d}}$} \\
\hline $\begin{array}{l}\text { Divorced/ } \\
\text { separated/widowed }\end{array}$ & 0.77 & 0.33 & 2.16 & {$[1.13,4.10]$} & $5.49 *$ \\
\hline Never married & 0.79 & 0.25 & 2.20 & {$[1.35,3.57]$} & ]10.09*** \\
\hline \multicolumn{6}{|l|}{ Race $^{\mathrm{e}}$} \\
\hline Black & 0.60 & 0.29 & 1.82 & {$[1.04,3.18]$} & $4.33^{*}$ \\
\hline Other & 0.18 & 0.39 & 1.20 & {$[0.56,2.56]$} & 0.21 \\
\hline $\begin{array}{l}\text { Income }^{f} \\
>\$ 60,000\end{array}$ & -0.03 & 0.21 & 0.97 & {$[0.64,1.47]$} & 0.02 \\
\hline \multicolumn{6}{|l|}{ Education ${ }^{\mathrm{g}}$} \\
\hline Some college & 0.06 & 0.21 & 1.06 & {$[0.70,1.61]$} & 0.07 \\
\hline $\begin{array}{l}\text { College/graduate } \\
\text { degree }\end{array}$ & 0.16 & 0.28 & 1.17 & {$[0.68,2.02]$} & 0.31 \\
\hline \multicolumn{6}{|l|}{$\begin{array}{l}\text { History of alcohol } \\
\text { abuse }\end{array}$} \\
\hline Yes & 0.84 & 0.51 & 2.31 & {$[0.86,6.22]$} & 2.73 \\
\hline \multicolumn{6}{|l|}{ Insurance status ${ }^{\mathrm{i}}$} \\
\hline Noninsured & -0.14 & 0.27 & 0.87 & {$[0.51,1.47]$} & 0.28 \\
\hline \multicolumn{6}{|l|}{ Deployment history ${ }^{\mathrm{j}}$} \\
\hline Deployed & 0.10 & 0.21 & 1.11 & {$[0.73,1.67]$} & 0.63 \\
\hline
\end{tabular}

Note. $N=2,259 . A O R=$ Adjusted odds ratio $\mathrm{CI}=$ confidence interval; $\mathrm{MDD}=$ major depressive disorder; PTSD = posttraumatic stress disorder; HIV = human immunodeficiency virus.

${ }^{a}$ Neither MDD nor PTSD served as the reference group. ${ }^{b}$ Men served as the reference group. ${ }^{\mathrm{c}}$ Ages 17-24 served as the reference group. ${ }^{\mathrm{d}}$ Married served as the reference group. ${ }^{e}$ White served as the reference group. ${ }^{\mathrm{f}}$ Less than or equal to $\$ 60,000$ served as the reference group. ${ }^{\mathrm{g}} \mathrm{High}$ school graduate served as the reference group. ${ }^{\mathrm{h}}$ No served as the reference group. ${ }^{\mathrm{i}}$ Insured served as the reference group. ${ }^{j}$ Never served as the reference group.

$* p<.05 .{ }^{* * *} p<.001$.

however, resulted in an HIV risk behavior prevalence greater than that observed in general population studies.

Our findings are also broadly consistent with an existing body of literature that has routinely demonstrated PTSD and depression to be positively associated with engagement in HIV risk behavior in nonmilitary populations (Alegría et al., 1994; Cavanaugh et al., 2010; Hutton et al., 2001; Perdue et al., 2003). Although there is a paucity of research examining the relationship between mental health problems and HIV risk in military personnel, an analysis of data from the 1992 National Survey of Veterans showed that persons with comorbid PTSD and substance abuse disorders were at a greatly elevated risk of HIV infection (Hoff, Beam-Goulet, \& Rosenheck, 1997). One recent study of soldiers in the Dominican Republic also found that PTSD was associated with sexual risk behavior (Tavarez et al., 2011). Although these aforementioned studies have demonstrated that PTSD is more strongly correlated with HIV risk behavior than depression (in contrast to our findings), neither examined the effect of comorbid mental health problems on HIV risk in a military population. Although further research is required, our results suggest that PTSD in the presence of other psychiatric conditions (e.g., depression) may have a greater influence on HIV risk behavior than PTSD on its own.

Although the cross-sectional nature of our work and these studies limit inference with respect to the causal relationship between PTSD, depression, and HIV risk, these findings suggest that interventions that aim to address psychiatric disorders among military personnel may have an ancillary benefit of reducing high-risk sex and drug-related behaviors. Irrespective of an underlying causal mechanism, our results indicate that soldiers suffering from both PTSD and depression should be the focus of future HIV prevention efforts. Although militaryfocused HIV prevention interventions have been implemented and are effective at reducing risk behavior in some settings (Bing et al., 2008; Ross et al., 2006; Russak, Ortiz, Galvan, \& Bing, 2005), to our knowledge no studies have evaluated the efficacy of HIV prevention programs specifically for military personnel with mental illness. Given the significant burden of mental health problems in this population (Kehle et al., 2011; Milliken, Auchterlonie, \& Hoge, 2007; Thomas et al., 2010), interventions that integrate psychiatric and HIV prevention services warrant development and evaluation.

A number of important study limitations must be noted. First, as the study instruments for the OHARNG Mental Health Initiative were not designed specifically to measure HIV risk, we were unable to conduct a thorough examination of behavioral risks for HIV acquisition in this population. For example, additional information regarding the context in which these behaviors take place (e.g., monogamous relationships or with casual partners of unknown serostatus) would have allowed for a deeper understanding of the true risks for HIV transmission experienced by soldiers of the OHARNG. Second, the crosssectional nature of our analysis precludes a causal interpretation of the observed associations. Third, we were not able to examine more antecedent components of the hypothesized etiologic pathway, including the potentially direct relationship between exposure to trauma and HIV risk behavior in the absence of PTSD. Fourth, a small number of participants were unable to recall the precise timing of these conditions and were excluded. Fifth, our measure of HIV risk was self-reported, and thus may be susceptible to underreporting, particularly given the stigmatized nature of the assessed behaviors. Although the higher prevalence of HIV risk behavior observed among participants completing the in-person clinical assessment does suggest some 
underreporting in the larger CATI sample, the relatively small difference of these values (i.e., $8.1 \%$ vs. $6.4 \%$ ) indicates that the magnitude of potential bias from underreporting is minimal. We cannot, however, exclude the possibility that HIV risk was underreported in both the CATI and clinical interviews. Sixth, the observed relationships between depression, PTSD, and HIV risk may be due to residual or unmeasured confounding. Finally, although our results are strictly generalizable to soldiers willing to participate in the research, we note that the characteristics of our sample are similar to those of the OHARNG (Calabrese et al., 2011), and are thus likely representative of the larger population.

In summary, this study demonstrated that mental health problems, notably PTSD and depression, were prevalent and associated with increased engagement in HIV risk behaviors among a sample of Ohio Army National Guard. These findings suggest that mental health problems including depression and PTSD play a role in augmenting vulnerability to HIV in this population. Given the expanding role of National Guard in combat operations and the commensurate increase in exposure to traumatic events, effective interventions are required to support soldiers at risk for HIV and prevent future infections.

\section{References}

Alegría, M., Vera, M., Freeman, D. H., Robles, R., Santos, M. C., \& Rivera, C. L. (1994). HIV infection, risk behaviors, and depressive symptoms among Puerto Rican sex workers. American Journal of Public Health, 84, 2000 2002. doi:10.2105/AJPH.84.12.2000

American Psychiatric Association. (1994). Diagnostic and statistical manual of mental disorders ( $4^{\text {th }}$ ed.). Arlington, VA: Author.

Anastario, M., Manzanero, R., Blanco, R., Reyes, E., Jaramillo, R., Black, L., ... Chun, H. (2011). HIV infection, sexual risk behaviour and condom use in the Belize defense force. International Journal of STD \& AIDS, 22 , 73-79. doi:10.1258/ijsa.2010.010274

Bensley, L. S., Van Eenwyk, J., \& Simmons, K. W. (2000). Self-reported childhood sexual and physical abuse and adult HIV-risk behaviors and heavy drinking. American Journal of Preventive Medicine, 18, 151-158. doi:10.1016/S0749-3797(99)00084-7

Bing, E. G., Cheng, K. G., Ortiz, D. J., Ovalle-Bahamon, R. E., Ernesto, F., Weiss, R. E., \& Boyer, C. B. (2008). Evaluation of a prevention intervention to reduce HIV Risk among Angolan soldiers. AIDS and Behavior, 12, 384 395. doi:10.1007/s10461-008-9368-2

Blake, D. D., Weathers, F. W., Nagy, L. M., Kaloupek, D. G., Gusman, F. D., Charney, D. S., \& Keane, T. M. (1995). The development of a clinician-administered PTSD scale. Journal of Traumatic Stress, 8, 75-90. doi:10.1002/jts.2490080106

Blanchard, E. B., Jones-Alexander, J., Buckley, T. C., \& Forneris, C. A. (1996). Psychometric properties of the PTSD Checklist (PCL). Behaviour Research and Therapy, 34, 669-673. doi:10.1016/0005-7967(96)00033-2

Boarts, J. M., Sledjeski, E. M., Bogart, L. M., \& Delahanty, D. L. (2006). The differential impact of PTSD and depression on HIV disease markers and adherence to HAART in people living with HIV. AIDS and Behavior, 10, 253-261. doi:10.1007/s10461-006-9069-7

Breiding, M. J., Black, M. C., \& Ryan, G. W. (2008). Chronic disease and health risk behaviors associated with intimate partner violence-
18 U.S. states/territories, 2005. Annals of Epidemiology, 18, 538-544. doi:10.1016/j.annepidem.2008.02.005

Breslau, N., Davis, G. C., Peterson, E. L., \& Schultz, L. (1997). Psychiatric sequelae of posttraumatic stress disorder in women. Archives of General Psychiatry, 54, 81-87. doi:10.1001/archpsyc.1997.01830130087016

Breslau, N., Davis, G. C. \& Schultz, L. R. (2003). Posttraumatic stress disorder and the incidence of nicotine, alcohol, and other drug disorders in persons who have experienced trauma. Archives of General Psychiatry, 60, 289-294. doi:10.1001/archpsyc.60.3.289

Brief, D. J., Bollinger, A. R., Vielhauer, M. J., Berger-Greenstein, J. A., Morgan, E. E., Brady, S. M., ... Keane, T. M. (2004). Understanding the interface of HIV, trauma, post-traumatic stress disorder, and substance use and its implications for health outcomes. AIDS Care, 16, S97-S120. doi:10.1080/09540120412301315259

Buckley, T. C., Mozley, S. L., Bedard, M. A., Dewulf, A. C., \& Greif, J. (2004) Preventive health behaviors, health-risk behaviors, physical morbidity, and health-related role functioning impairment in veterans with post-traumatic stress disorder. Military Medicine, 169, 536-540. PMID: 15291186.

Calabrese, J. R., Prescott, M., Tamburrino, M., Liberzon, I., Slembarski, R., Goldmann, E., ... Galea, S. (2011). PTSD comorbidity and suicidal ideation associated with PTSD within the Ohio Army National Guard. The Journal of Clinical Psychiatry, 72, 1072-1078. doi:10.4088/JCP.11m06956

Cavanaugh, C. E., Hansen, N. B., \& Sullivan, T. P. (2010). HIV sexual risk behavior among low-income women experiencing intimate partner violence: The role of posttraumatic stress disorder. AIDS and Behavior, 14, 318-327. doi:10.1007/s10461-009-9623-1

Centers for Disease Control and Prevention. (2011, January 27). $2011 \mathrm{Be}$ havioral Risk Factor Surveillance System Questionnaire. Retrieved from http://www.cdc.gov/brfss/questionnaires/pdf-ques/2011brfss.pdf

Davidson, J. R., Hughes, D., Blazer, D. G., \& George, L. K. (1991). Posttraumatic stress disorder in the community: an epidemiological study. Psychological Medicine, 21, 713-721. doi:10.1017/S0033291700022352

El-Bassel, N., Gilbert, L., Vinocur, D., Chang, M., \& Wu, E. (2011). Posttraumatic stress disorder and HIV risk among poor, inner-city women receiving care in an emergency department. American Journal of Public Health, 101, 120-127. doi:10.2105/AJPH.2009.181842

First, M. B., Spitzer, R. L., Gibbon, M., \& Williams, J. B. W. (2002). Structured Clinical Interview for the DSM-IV-TR Axis I Disorders, Research Version, Non-Patient Edition. (SCID-I/NP). New York: New York State Psychiatric Institute, Biometrics Research.

Hoff, R. A., Beam-Goulet, J., \& Rosenheck, R. A. (1997). Mental disorder as a risk factor for human immunodeficiency virus infection in a sample of veterans. The Journal of Nervous and Mental Disease, 185, 556-560. doi:10.1097/00005053-199709000-00004

Holmes, W. C., Foa, E. B., \& Sammel, M. D. (2005). Men's pathways to risky sexual behavior: Role of co-occurring childhood sexual abuse, posttraumatic stress disorder, and depression histories. Journal of Urban Health, 82, 189 199. doi:10.1093/jurban/jti028

Hutton, H. E., Treisman, G. J., Hunt, W. R., Fishman, M., Kendig, N., Swetz, A., \& Lyketsos, C. G. (2001). HIV risk behaviors and their relationship to posttraumatic stress disorder among women prisoners. Psychiatric Services, 52, 508-513. doi:10.1176/appi.ps.52.4.508

Kehle, S. M., Reddy, M. K., Ferrier-Auerbach, A. G., Erbes, C. R., Arbisi, P. A., \& Polusny, M. A. (2011). Psychiatric diagnoses, comorbidity, and functioning in National Guard troops deployed to Iraq. Journal of Psychiatric Research, 45, 126-132. doi:10.1016/j.jpsychires.2010.05.013

Kroenke, K., \& Spitzer, R. L. (2002). The PHQ-9: A new depression diagnostic and severity measure. Psychiatric Annals, 32, 509-515. 
Kroenke, K., Spitzer, R. L., \& Williams, J. B. (2001). The PHQ-9: Validity of a brief depression severity measure. Journal of General Internal Medicine, 16, 606-613. doi:10.1046/j.1525-1497.2001.016009606.x

Lehrer, J. A., Shrier, L. A., Gortmaker, S., \& Buka, S. (2006). Depressive symptoms as a longitudinal predictor of sexual risk behaviors among US middle and high school students. Pediatrics, 118, 189-200. doi:10.1542/peds.20051320

Levin, L. I., Peterman, T. A., Renzullo, P. O., Lasley-Bibbs, V., Shu, X. O., Brundage, J. F., \& McNeil, J. G. (1995). HIV-1 seroconversion and risk behaviors among young men in the US army. The Seroconversion Risk Factor Study Group. American Journal of Public Health, 85, 1500-1506. doi:10.2105/AJPH.85.11.1500

Link, M. W., Battaglia, M. P., Frankel, M. R., Osborn, L., \& Mokdad, A. H. (2006). Address-based versus random-digit-dial surveys: Comparison of key health and risk indicators. American Journal of Epidemiology, 164, 1019-1025. doi:10.1093/aje/kwj310

Maguen, S., Lucenko, B. A., Reger, M. A., Gahm, G. A., Litz, B. T., Seal, K. H., ... Marmar, C. R. (2010). The impact of reported direct and indirect killing on mental health symptoms in Iraq war veterans. Journal of Traumatic Stress, 23, 86-90. doi:10.1002/jts.20434

Milliken, C. S., Auchterlonie, J. L., \& Hoge, C. W. (2007). Longitudinal assessment of mental health problems among active and reserve component soldiers returning from the Iraq war. Journal of the American Medical Association, 298, 2141-2148. doi:10.1001/jama.298.18 .2141

Ohl, M. E., \& Perencevich, E. (2011). Frequency of human immunodeficiency virus (HIV) testing in urban vs. rural areas of the United States: Results from a nationally-representative sample. BMC Public Health, 11, 681. doi:10.1186/1471-2458-11-681

Perdue, T., Hagan, H., Thiede, H., \& Valleroy, L. (2003). Depression and HIV risk behavior among Seattle-area injection drug users and young men who have sex with men. AIDS Education and Prevention, 15, 81-92. doi:10.1521/aeap.15.1.81.23842

Phillips-Salimi, C. R., Lommel, K., \& Andrykowski, M. A. (2012). Physical and mental health status and health behaviors of childhood cancer survivors: Findings from the 2009 BRFSS survey. Pediatric Blood \& Cancer, 58, 964-970. doi:10.1002/pbc.23359

Plotzker, R. E., Metzger, D. S., \& Holmes, W. C. (2007). Childhood sexual and physical abuse histories, PTSD, depression, and HIV risk outcomes in women injection drug users: A potential mediating pathway. The American Journal on Addictions, 16, 431-438. doi:10.1080/10550490701643161

Reisner, S. L., Mimiaga, M. J., Safren, S. A., \& Mayer, K. H. (2009). Stressful or traumatic life events, post-traumatic stress disorder (PTSD) symptoms, and HIV sexual risk taking among men who have sex with men. AIDS Care, 21, 1481-1489. doi:10.1080/09540120902893258
Rietmeijer, C. A., Lansky, A., Anderson, J. E., \& Fichtner, R. R. (2001). Developing standards in behavioral surveillance for HIV/STD prevention. AIDS Education and Prevention, 13, 268-278. doi:10.1521/aeap.13.3.268.19740

Ross, M. W., Essien, E. J., Ekong, E., James, T. M., Amos, C., Ogungbade, G. O., \& Williams, M. L. (2006). The impact of a situationally focused individual human immunodeficiency virus/sexually transmitted disease riskreduction intervention on risk behavior in a 1-year cohort of Nigerian military personnel. Military Medicine, 171, 970-975.

Russak, S. M., Ortiz, D. J., Galvan, F. H., \& Bing, E. G. (2005). Protecting our militaries: A systematic literature review of military human immunodeficiency virus/acquired immunodeficiency syndrome prevention programs worldwide. Military Medicine, 170, 886-897.

Schnurr, P. P., \& Spiro, A. (1999). Combat exposure, posttraumatic stress disorder symptoms, and health behaviors as predictors of self-reported physical health in older veterans. The Journal of Nervous and Mental Disease, 187, 353-359. doi:10.1097/00005053-199906000-00004

Sledjeski, E. M., Delahanty, D. L., \& Bogart, L. M. (2005). Incidence and impact of posttraumatic stress disorder and comorbid depression on adherence to HAART and CD4+ counts in people living with HIV. AIDS Patient Care \& STDS, 19, 728-736. doi:10.1089/apc.2005.19.728

Tavarez, M. I., Chun, H., \& Anastario, M. P. (2011). Correlates of sexual risk behavior in sexually active male military personnel stationed along bordercrossing zones in the Dominican Republic. American Journal of Men's Health, 5, 65-77. doi:10.1177/1557988310362097

Thomas, J. L., Wilk, J. E., Riviere, L. A., McGurk, D., Castro, C. A., \& Hoge, C. W. (2010). Prevalence of mental health problems and functional impairment among active component and National Guard soldiers 3 and 12 months following combat in Iraq. Archives of General Psychiatry, 67, 614-623. doi:10.1001/archgenpsychiatry.2010.54

Vranceanu, A. M., Safren, S. A., Lu, M., Coady, W. M., Skolnik, P. R., Rogers, W. H., \& Wilson, I. B. (2008). The relationship of post-traumatic stress disorder and depression to antiretroviral medication adherence in persons with HIV. AIDS Patient Care \& STDS, 22, 313-321. doi:10.1089/apc.2007.0069

Wen, X. J., Balluz, L., \& Town, M. (2012). Prevalence of HIV risk behaviors between binge drinkers and non-binge drinkers aged 18- to 64-years in US, 2008. Journal of Community Health, 37, 72-79. doi:10.1007/s10900-0119418-y

Williams, C. T., \& Latkin, C. A. (2005). The role of depressive symptoms in predicting sex with multiple and high-risk partners. Journal of Acquired Immune Deficiency Syndromes, 38, 69-73. doi:10.1097/00126334-20050101000013

Zatzick, D. F., Marmar, C. R., Weiss, D. S., Browner, W. S., Metzler, T. J., Golding, J. M., ... Wells, K. B. (1997). Posttraumatic stress disorder and functioning and quality of life outcomes in a nationally representative sample of male Vietnam veterans. American Journal of Psychiatry, 154, $1690-1695$. 